Published in final edited form as:

Semin Nephrol. 2008 May ; 28(3): 306-317. doi:10.1016/j.semnephrol.2008.03.003.

\title{
Vasopressin antagonists in polycystic kidney disease
}

\author{
Vicente E. Torres \\ Mayo Clinic College of Medicine, Rochester, Minnesota, Division of Nephrology, Mayo Clinic \\ College of Medicine, 200 First Street SW, Rochester, MN 55905
}

\begin{abstract}
Autosomal dominant polycystic kidney disease (ADPKD) is the most common of the inherited renal cystic diseases and a leading cause of ESRD (1). It is genetically heterogeneous with two genes identified, $P K D 1$ and $P K D 2$. Autosomal recessive polycystic kidney disease (ARPKD) is less common than ADPKD, but together with nephrophthisis, is the leading cause of ESRD in childhood. It is caused by mutations to PKHD1 (2). Currently there is no effective therapy for these diseases. Advances in the understanding of cystogenesis and availability of genetically related animal models provide unique opportunities to develop effective treatments. This article summarizes recent advances raising the hope that vasopressin V2 receptor antagonists will become a safe and effective therapy for PKD.
\end{abstract}

\section{Pathogenesis of Polycystic Kidney Disease}

The cloning of PKD1 and PKD2 in 1994 and 1996 (3-6) and of PKHD1 in 2002(7-9) were major steps towards the understanding of polycystic kidney disease. The proteins encoded by these genes are membrane associated proteins. Polycystin-2 (PC2 or TRPP2), the protein encoded by PKD2, is a TRP channel with high permeability to calcium. Polycystin-1 (PC1) and fibrocystin/polyductin (FC/PD) are thought to be cell surface receptors that directly in the case of PC1 $(10,11)$ or indirectly in the case of FC $(12)$ interact with and regulate the channel function of PC2. PC1 and FC/PD also have other functions, some of which are in turn regulated by $\mathrm{PC} 2$. For example, $\mathrm{PC} 2$ binding to $\mathrm{PC} 1$ reduces the ability of PC1 to constitutively activate G-proteins (13).

PCs and FC/PD are multifunctional proteins with numerous interacting partners that are essential to maintain the differentiated phenotype of the tubular epithelium (14). Reduction in one of these proteins below a critical level induces changes in protein trafficking and targeting, cell-matrix and cell-cell interactions, proliferation and apoptosis, planar polarity, and fluid secretion that result in the initiation and growth of cysts (15). The underlying molecular mechanisms are complex. The PCs and FC/PD participate in kinase cascades that connect interactions at cell-matrix and cell-cell contacts to the regulation of nuclear transcription and cell differentiation (16-18). PC1 and FC may also undergo regulated intramembrane proteolysis, a process initiated by ligand binding that releases cytoplasmic peptide fragments that migrate to the nucleus and affect transcription (19-22).

\footnotetext{
(c) 2008 Elsevier Inc. All rights reserved.

Corresponding Author: Vicente E. Torres, M.D., Division of Nephrology, Mayo Clinic, 200 First Street SW, Rochester, MN 55905, torres.vicente@ mayo.edu, (507) 284-7572 (phone), (507) 266-9315 (fax).

Publisher's Disclaimer: This is a PDF file of an unedited manuscript that has been accepted for publication. As a service to our customers we are providing this early version of the manuscript. The manuscript will undergo copyediting, typesetting, and review of the resulting proof before it is published in its final citable form. Please note that during the production process errors may be discovered which could affect the content, and all legal disclaimers that apply to the journal pertain.
} 
The role of the PKD proteins in primary cilia and regulation of intracellular calcium homeostasis has received the most attention. PC1, PC2 and FC/PD are located in primary cilia (23-25). In the primary cilia, the PC/FC complex senses and translates mechanical stimulation into Ca entry, which triggers calcium-induced calcium release from the ER (2628). PC2 is also present in the ER where it interacts with other calcium channels, the IP3R and RR (29-32). Together, PC2, IP3R and RR are responsible for Ca release from intracellular stores. Reductions in the levels of PCs or FC below a critical threshold impair intracellular Ca homeostasis $(33,34)$. In renal tubular epithelial cells, intracellular calcium limits cAMP accumulation by inhibiting AC6 and stimulating PDE1 (35-37). This may account for the renal accumulation of cAMP in animal models of ADPKD and ARPKD (3841). Cyclic AMP stimulates cell proliferation and chloride (CFTR-mediated) driven fluid secretion (42-44). While under normal conditions cAMP inhibits MAP kinase signaling and cell proliferation, in conditions of $\mathrm{Ca}$ deprivation such as in polycystic kidney disease it stimulates cell proliferation in a src, ras and b-raf dependent manner. This proliferative effect may be further enhanced by the stimulation of mislocalized Erb-B receptors by EGFlike factors present in cyst fluid (45). The signaling pathways activated downstream from mutated PC1 converge with those activated in tuberous sclerosis complex, possibly due to disruption of the physical interaction between $\mathrm{PC} 1$ and tuberin or to phosphorylation of tuberin by MAPK and Akt leading to activation of mTOR (46).

\section{Opportunities for intervention}

The increased understanding of the molecular mechanisms of polycystic kidney disease has provided a number of targets for therapeutic intervention (Figure 1). Triptolide binds to PC2, induces Ca release by a PC2 dependent mechanism, and ameliorates cystic disease in a Pkd1 animal model (47). Consistent with observations of milder disease in patients who have ADPKD and cystic fibrosis $(48,49)$, CFTR inhibitors inhibit the development of cysts by MDCK cells in collagen gels (50) and in metanephric organ cultures (51) by inhibiting chloride secretion. How to apply this strategy without inducing cystic fibrosis will be challenging. Erb-B tyrosine kinase inhibitors have been used successfully in a variety of models, but different Erb-B receptors seem to be important in different animal models (45, 52-55). These drugs have significant toxicity, which may limit their use for extended periods of time. The same can be said for src, mek and cdk inhibitors (56-58). This concern is less for mTOR inhibitors thanks to the extensive experience with this drug in transplantation $(46,59,60)$.

\section{Rationale for therapies targeting the AVP-V2 receptor axis and renal cAMP}

Targeting strategies that minimize the effects of a medication on normal cells are essential in chronic diseases that require long-term treatments. The central role of cAMP in the pathogenesis of PKD and the ability to hormonally modulate cAMP in a cell-specific manner provide opportunities for such strategies in PKD. Among various hormonal systems that may influence the development of PKD, a combination of favorable factors make the arginine vasopressin (AVP)- AVP V2 receptor axis a particularly attractive target:

A. The cysts in PKD derive predominantly from vasopressin sensitive tubular segments expressing V2 receptors, i.e. the collecting duct and the distal nephron. While there is general agreement that the cysts in ARPKD and nephronophthisis derive from collecting ducts, a careful review of the literature indicates that cysts in ADPKD and in slowly progressive Pkd1 and Pkd2 animal models derive predominantly from collecting duct and distal nephron (61). The expression of V2 receptors is strong in the medullary thick ascending limb, macula densa, and medullary collecting duct, intermediate in connecting tubule and cortical collecting duct, and low in cortical thick ascending limb and distal convoluted tubule (62). 
B. Vasopressin acting on V2 receptors is the main hormonal regulator of adenylyl cyclase activity in freshly dissected collecting ducts (63). The V2 induced effects on cAMP and water permeability may be limited by the action of AVP on V1a receptors on apical and basolateral membranes, stimulating phospholipase $\mathrm{C}$, phosphoinositide hydrolysis and $\mathrm{Ca}^{2+}$ release from the endoplasmic reticulum (64).

C. To avoid dehydration mammals live under the constant tonic action of AVP on the distal nephron and collecting duct (65-68). Only after drinking large volumes of liquid do plasma AVP levels decrease enough to render the urine more dilute than plasma. Thus, during most of the day, cyst epithelial cells are persistently stimulated to proliferate and secrete fluid.

D. The circulating levels of AVP are increased in human ADPKD and in all animal models where it has been ascertained (69-71). This may be due to a central defect (72) or, more likely, to compensate for the reduced concentrating capacity of the polycystic kidneys. This concentrating defect may be due to the disruption of the corticomedullary architecture by the cysts, early development of tubulointerstitial disease or directly linked to the PKD cellular phenotype (73). The upregulation of aquaporin 2 (AQP2) in polycystic kidneys (38-40,73), in sharp contrast to other forms of nephrogenic diabetes insipidus, suggest enhanced vasopressin activity and a defect distal to the production of AQP2.

E. In contrast to the $\mathrm{V} 2$ receptor downregulation in other conditions with persistently elevated AVP (74), the V2 receptor is overexpressed in polycystic kidneys (38-40, 73). This is probably due to the upregulation of the $\mathrm{V} 2$ receptor promoting activity by cAMP (75).

F. The restricted expression of V2 receptors to epithelial cells of the distal nephron and collecting duct (62) and on endothelial cells, where it has been implicated in the secretion of von Willebrand factor (76), suggest that V2 antagonists are likely to be well tolerated. Indeed, there is already considerable experience with these compounds in clinical trials for congestive heart failure and hyponatremia. These have as main side effects an expected mild to moderate thirst and dry mouth, and increased urination that are all generally well tolerated (77-81).

\section{Preclinical trials of Vasopressin V2 receptor antagonists}

Gattone et al initially reported that administration of an AVP receptor antagonist ameliorated the cystic enlargement and azotemia in a mouse model of rapidly progressive renal cystic disease (73). To test the effects of AVP V2 receptor antagonists in animal models orthologous to human diseases, we have used two compounds, OPC-31260 and tolvaptan. OPC-31260, a strong antagonist of the V2 receptor in rodents that is 82 times more selective for rat V2 receptors than for rat V1a receptors (82). Because OPC-31260 is a relatively weak antagonist of the human V2 receptor, we have also used tolvaptan, a stronger antagonist for the human receptor ( $K i$ value 22 times higher than that for OPC-31260), which is 29 times more selective for human V2 receptors than for human V1a receptors (82).

The PCK rat is a model of human ARPKD caused by a splicing mutation (IVS35-2A $\rightarrow$ T) that skips exon 36 and leads to a frameshift in Pkhd1. Administration of OPC-31260 to PCK rats between three and ten weeks of age reduced the renal accumulation of cAMP and Ras and ERK activation, and inhibited disease development, as reflected by lower kidney weights, plasma creatinine and BUN concentrations, renal cyst volumes, and mitotic and apoptotic indices $(38,40)$. By comparing the kidney weights of the treated and untreated PCK rats to those of 10 week-old wild-type Sprague-Dawley rats, the estimated degree of 
protection was $60 \%$ to $75 \%$ depending on the dose. Administration of OPC-31260 from ten to eighteen weeks of age reduced the renal accumulation of cAMP and inhibited disease progression, as reflected by lower kidney weights, plasma creatinine and BUN concentrations, renal cyst and fibrosis volumes, mitotic and apoptotic indices, and systolic blood pressures. The weights of the kidneys at eighteen weeks of age in the treated rats were identical to those of the control PCK rats at 10 weeks of age, indicating that the administration of OPC-31260 completely halted disease progression. OPC-31260 did not have a significant effect on the fibropolycystic liver disease, consistent with the absence of VP-V2 receptors in the liver.

The $P k d^{-/ W S 25}$ mouse is a double heterozygote for a $P k d 2$ null allele and an unstable $P k d 2$ WS25 mutation. It is a model of human ADPKD (PKD2) that reliably develops renal cysts within three months. OPC-31260, administered in the diet to $P k d 2^{-/ W S 25}$ mice between 3 and 16 weeks of age, reduced the renal accumulation of cAMP and inhibited disease development, as reflected by lower kidney weights, plasma BUN concentrations, renal cyst and fibrosis volumes, and mitotic and apoptotic indices (39). The kidney weights of treated $P k d 2^{-/ W S 25}$ mice were similar to wild-type, indicating that renal enlargement was prevented. OPC-31260 did not have a significant effect on polycystic liver disease.

The pcy mouse is a model of nephronophthisis caused by a missense mutation in NPHP3, the gene mutated in adolescent nephronophthisis. Administration of OPC-31260 to CD1/pcy mice between four and thirty weeks of age inhibited the renal accumulation of cAMP and disease development, as reflected by lower kidney weights, plasma BUN concentrations, renal cyst and fibrosis volumes, and mitotic and apoptotic indices (38). Administration of OPC-31260 to CD1/pcy mice between fifteen and thirty weeks of age also inhibited the renal accumulation of cAMP levels and disease progression, as reflected by the lower kidney weights, plasma BUN concentrations, renal cyst and fibrosis volumes, and mitotic and apoptotic indices. Kidney weights of mice started on treatment at fifteen weeks and killed at thirty weeks of age were significantly lower than those of untreated mice at fifteen weeks of age. This suggests that OPC-31260 not only halted disease progression but also induced disease regression.

To confirm that tolvaptan, a V2 receptor antagonist used in clinical trials for hyponatremia and congestive heart failure, is also capable of inhibiting the development of polycystic kidney disease, this compound was administered to the same animal models of polycystic kidney disease. In the three models, the administration of tolvaptan reduced the renal enlargement and cystic pathology $(40,83,84)$.

\section{Modulation of renal cystogenesis by circulating vasopressin}

To confirm that the protective effect of $\mathrm{V} 2$ receptor antagonists is indeed due to $\mathrm{V} 2 \mathrm{R}$ antagonism, we generated PCK $A V P^{+/+}$, PCK $A V P^{+/}$, and PCK $A V P^{-/-}$rats, as well as wild-type and Brattleboro controls, by breeding F1 rats resulting from PCK $\left(P k h d 1^{-1-}\right)$ and Brattleboro $\left(A V P^{-/-}\right)$crosses. Brattleboro rats are homozygous for a 1-bp deletion of a guanine nucleotide in the second exon of the $A V P$ gene and lack circulating AVP. At 10 and 20 weeks of age PCK $A V P^{-/-}$rats exhibited polyuria and reduced renal cAMP compared to the PCK $A V P^{+/ t}$ rats (85). This was accompanied by a marked reduction in kidney weight and renal cyst and fibrosis volumes.

To confirm that the protective effect of AVP deficiency on the development of polycystic kidney disease is due the lack of stimulation of the renal V2 receptors, PCK $A V P^{-/-}$, PCK $A V^{+/+}$, and wild type rats were treated with the V2 agonist 1-deamino-8-D-arginine vasopressin (DDAVP) administered via osmotic minipumps at a dose of $10 \mathrm{ng} / \mathrm{hr} / 100 \mathrm{gm}$ body weight between 10 and 20 weeks of age (85). This dose is the minimal dose necessary 
to achieve urine osmolalities in Brattleboro rats similar to those observed in wild type Sprague Dawley rats. Administration of DDAVP to PCK $A V P^{-/-}$corrected the polyuria, increased the renal concentration of cAMP, recovered the full cystic PCK phenotype as reflected by the kidney weights, and cyst and fibrosis indices, and significantly increased the plasma BUN concentrations. Administration of DDAVP to PCK $A V P^{t /+}$ rats increased the severity of polycystic kidney disease, as reflected by significantly higher kidney weights, cyst and fibrosis indices, and plasma BUN concentrations. Administration of DDAVP to wild type rats at the dose used in this study caused a slight but significant increase in renal mass per unit of body weight without inducing cystic changes or fibrosis. This is consistent with previous reports of selective AVP-induced hypertrophy of the medullary thick ascending limb in Brattleboro rats $(86,87)$.

A non-genetic approach to suppress vasopressin action also supports the importance of vasopressin in the modulation of renal cystogenesis. Addition of 5\% glucose in the drinking water increased fluid intake and urine output 3.5-fold, reduced urinary AVP excretion, AVP V2 receptor expression and ERK activation, inhibited proliferation, reduced the severity of the cystic disease, and improved renal function (88).

\section{Other observations supporting an effect of vasopressin on renal cystogenesis}

The long-acting somatostatin analogue octreotide and the endothelin $\mathrm{ET}_{\mathrm{B}}$ receptor antagonist A-192621 have been reported to have opposing effects in animal models orthologous to human polycystic kidney disease that may be mediated by opposing effects on vasopressin stimulated cAMP accumulation in the kidney. The administration of octreotide to PCK rats lowers cAMP levels and inhibits the development of polycystic kidney disease, while the administration of A-192621 to $P k d 2^{-/ W S 25}$ mice increases urine osmolarity and renal cAMP and aggravates the severity of the cystic disease $(89,90)$. At physiological concentrations somatostatin inhibits vasopressin induced cAMP generation and water permeability via Gi coupled SSTR1 and SSTR2 receptors which are predominantly located in the distal nephron and collecting tubule (91-93). On the other hand, endothelin-1 acting via ETB receptors, the predominant endothelin receptor subtype in the collecting tubules, inhibits vasopressin action and promotes diuresis (94).

\section{Other potential benefits of AVP V2 receptor antagonists in polycystic kidney disease}

In addition to its effects on cystogenesis, AVP may have effects on blood pressure and renal function that may be relevant to the progression of polycystic kidney disease:

A. Effects on blood pressure. The inverse correlation between urine concentrating capacity and average 24-hour blood pressures in children with ADPKD (71) and the correlation between urine volume and mean arterial blood pressure in MDRD study participants with ADPKD(95) suggest that the increased circulating levels of AVP observed in ADPKD may contribute to the development of hypertension, one of the most common manifestations of this disease. AVP effects on blood pressure are mediated by V1a and V2 receptors. V1a receptor activation may increase blood pressure by a direct effect on vascular smooth muscle and by reducing medullary renal blood flow and pressure natriuresis (96). V2 receptor activation enhances beta and gamma epithelial sodium channel (EnaC) expression and EnaC function and acts synergistically with aldosterone in the cortical collecting duct (97-99). On the other hand $\mathrm{V} 2$ receptor activation may also exert an antihypertensive effect by inducing NO synthesis in collecting ducts and increasing medullary blood flow 
(100). Impaired NO synthesis, which has been reported in human ADPKD and in animal models of polycystic kidney disease $(101,102)$, may be a prerequisite for the pro-hypertensive effect of vasopressin.

B. CKD progression. AVP levels are increased in CKD (103) and Bankir et al. have proposed that this contributes importantly to disease progression (104-107). AVP (or exogenous dDAVP) elevates urea and lowers $\mathrm{NaCl}$ concentrations in the thick ascending limb of Henle and at the macula densa by increasing intrarenal urea recycling. This results in a suppression of tubuloglomerular feedback and a stimulation renin secretion that may lead to glomerular hyperfiltration, albuminuria, renal hypertrophy, and tubulointerstitial disease. In support of this hypothesis, suppression of circulating AVP in 5/6 nephrectomized rats by doubling the daily water ingestion has been shown to reduce proteinuria, blood pressure, renal hypertrophy, glomerulosclerosis, and tubulointerstitial fibrosis $(106,108)$. The attenuation of renal disease progression in 5/6 nephrectomized Brattleboro is reversed by the administration of dDAVP, suggesting that $\mathrm{V} 2$ receptors play a major role in the deleterious influence of vasopressin on disease progression (105). Contrary to these observations, a retrospective analysis of Modification of Diet in Renal Disease (MDRD) patients with baseline GFRs 25 to $55 \mathrm{~mL} / \mathrm{min} / 1.73 \mathrm{~m}^{2}$ raised the possibility that a high fluid intake could be detrimental to patients with chronic renal insufficiency, particularly to those with ADPKD (95). The patients with the greater urine volumes and the lowest urine osmolalities experienced the fastest GFR declines. Since they tended to have lower serum sodium concentrations and had urines hypotonic to plasma, the authors concluded that excess water intake and not a renal concentrating caused the high urine volume. Further studies will be necessary to elucidate the potential beneficial or detrimental effects of high fluid intake in ADPKD patients with renal insufficiency.

\section{Clinical trials of vasopressin V2 receptor antagonists}

The observations in animal models of polycystic kidney disease strongly suggest that AVP is a powerful modulator of cystogenesis and provide support for clinical trials of V2 receptor antagonists in this disease. TEMPO stands for Tolvaptan Efficacy and Safety in

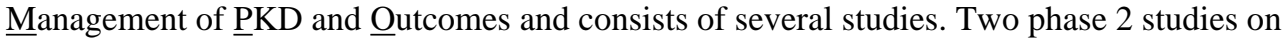
the safety, pharmacokinetics, and pharmacodynamics of tolvaptan tablets in ADPKD included 11 and 37 volunteers, 18-60 years old, with a serum creatinine $<1.8 \mathrm{mg} / \mathrm{dL}$, randomized to oral placebo or tolvaptan (109-111). Each study began with a 1 day baseline. Patients drank ad lib and recorded fluid intake and output.

Study A was a randomized placebo controlled ( 8 treatment, 3 placebo), ascending dose ( 0 , $15,30,60$, and $120 \mathrm{mg}$ administered 72 hours apart) study. Urines were collected $0-4,4-8$, $8-12,12-16$, and 16-24 hours post-dosing. Tolvaptan caused dose dependent increases in urine output and reductions in urine osmolality and AQP2 excretion, without significant changes in cAMP excretion. AQP2 excretion changes paralleled those in UO. A significant increase in plasma AVP of 2- to 3-fold was seen at the highest dose of tolvaptan $(<0.03$ at 24 $\mathrm{h}$ post- $120 \mathrm{mg}$ ), when compared to its own baseline although the difference from the $P$ group only reached a trend $(\mathrm{p}=0.06)$. The maximum means observed at any time were 4.1 (tolvaptan) and $3.2 \mathrm{ng} / \mathrm{L}$ (placebo). Hypostenuria was sustained during 4-16 hours postdosing, but UO increased above $300 \mathrm{mOsm} / \mathrm{L}$ in $5 / 8(15 \mathrm{mg}), 2 / 8(30 \mathrm{mg})$ and $1 / 8(60 \mathrm{mg})$ patients 16-24 hours post-dosing. These results indicate that cAMP production may not be inhibited beyond 16 hours post-dosing, AQP2 excretion is not superior to UO to monitor the response, and cAMP excretion is not a good marker of cAMP production in the renal medulla. 
In Study B, subjects took tolvaptan at $15 / 15,30 / 0,30 / 15$ or 30/30 mg twice daily ( $8 \mathrm{AM}$ and 4 PM) administration for 5 days. Mean urine output increased an average from between $2974-4586 \mathrm{~mL} /$ day by a further 2974 to $4586 \mathrm{~mL}$ on day 1 declining to a further 1764 to $2274 \mathrm{~mL}$ on day 5 . A negative fluid balance was seen on acute introduction of tolvaptan ( -708 to $-901 \mathrm{~mL}$ ), however this equilibrated by day 5 of Study B ( -99 to $+558 \mathrm{~mL}$ ). AVP increased dose-dependently with variable significance compared to baseline. For the highest dose, the mean level at day 5 remained in the mid-normal range $1-3 \mathrm{ng} / \mathrm{L}$. Twice daily administration was necessary for adequate suppression of the vasopressin effect reflected by persistent urine hypotonicity and the best result was obtained with the administration of 30 mg twice daily.

In both studies, tolvaptan dose-dependently induced modest increases in serum sodium and osmolality, without changes in other electrolytes. No appreciable changes in vital signs were noted. Thirst appropriately maintained fluid intake. No serious adverse events were reported and no one discontinued tolvaptan in either study. In Study A, 21 mild and 3 moderate level side effects were reported in the tolvaptan $(\mathrm{n}=8)$ and 4 mild and 1 moderate level side effect in the placebo group ( $\mathrm{n}=3$ ). In Study B a total of 35 mild and 6 moderate side effects were reported in 21/37 subjects. Dry mouth was the most frequently reported side effect and was not clearly dose dependent.

The pharmacokinetic profile of oral tolvaptan in ADPKD individuals was similar to a healthy control population. In summary, tolvaptan was well tolerated throughout a range of doses and when administered once or twice a day in ADPKD individuals with normal renal function. Twice daily administration was necessary for adequate suppression of the vasopressin effect reflected by persistent urine hypotonicity.

Forty-six of the 48 participants in the previous phase 2 tolvaptan studies with a GFR $>30$ $\mathrm{mL} / \mathrm{min}$ were enrolled in a 3 -year, open label, phase 2 clinical trial to acquire tolerability, long-term safety and pilot efficacy data (112). Initially, tolvaptan was administered in ascending doses of $15 / 15,30 / 15,45 / 15,60 / 30$ or $90 / 30 \mathrm{mg}$ PO twice daily (8 AM and $4 \mathrm{PM}$ ) beginning at $30 / 15 \mathrm{mg}$ to establish maximal tolerated and minimum effective doses (titration phase); 96,61 and $46 \%$ of subjects said they could tolerate $45 / 15,60 / 30$ and $90 / 30$ doses for the rest of their life. Subjects were then randomized to a low $(45 / 15, n=22)$ or a high $(60 / 30$, $\mathrm{n}=24$ ) dose extended therapy. Sixteen of the planned 36-month followups had been completed at the time of the last report. Average daily doses have been 59.7 and $82.5 \mathrm{mg}$. Polyuria has been well tolerated. Median urine osmolalities have ranged 165-253, 123-154 and $108-152 \mathrm{mOsm} / \mathrm{L}$ before AM and PM doses and at bedtime. Serum creatinine increased from 1.20 and $1.36 \mathrm{mg} / \mathrm{dL}$ at baseline to 1.36 and $1.49 \mathrm{mg} / \mathrm{dL}$ at two months, but had returned towards the baseline level at sixteen months $(1.27$ and $1.39 \mathrm{mg} / \mathrm{dL})$ in the low and high dose groups, respectively. The administration of tolvaptan was accompanied by slight, but sustained reduction in serum BUN and increase in serum uric acid. Serum sodium concentrations at 2 and 16 months were unchanged from baseline. Serious adverse events led to discontinuation of tolvaptan in 4 subjects: These included a reversible increase in serum creatinine from 1.4 to $1.7 \mathrm{mg} / \mathrm{d}$, left periorbital swelling, atrial fibrillation with transient ischemic episode, and pituitary microadenoma. In summary, these preliminary results from this open label study suggest that a split dose regimen of tolvaptan is well tolerated, appears to be safe and is able to sustain urine hypotonicity.

A phase 3, multi-center, double-blind, placebo-controlled, parallel-arm trial of split dose regimens of tolvaptan has been initiated in 18-50 yr old patients, with relatively rapid progression, as indicated by a TKV $>750 \mathrm{~mL}$, and relatively preserved renal function as reflected by an estimated GFR $>60 \mathrm{~mL} / \mathrm{min}$. The primary outcome measure is renal volume 
change by MR. This clinical trial is expected to enroll 1200-1500 participants with 3 years duration of treatment (www.ClinicalTrials.gov Identifier NCT00428948 [fc1] $)$.

\section{Acknowledgments}

Supported by the National Institutes of Health grant DK44863

\section{References}

1. Torres VE, Harris PC, Pirson Y. Autosomal dominant polycystic kidney disease. Lancet. 2007; 369:1287-1301. [PubMed: 17434405]

2. Gunay-Aygun M, Avner ED, Bacallao RL, et al. Autosomal recessive polycystic kidney disease and congenital hepatic fibrosis: Summary statement of a First National Institutes of Health/Office of Rare Diseases conference. J Pediatr. 2006; 149:159-164. [PubMed: 16887426]

3. American PKD1 Consortium. Analysis of the genomic sequence for the autosomal dominant polycystic kidney disease $(P K D 1)$ gene predicts the presence of a leucine-rich repeat. Hum Mol Genet. 1995; 4:575-582. [PubMed: 7633406]

4. Hughes J, Ward CJ, Peral B, et al. The polycystic kidney disease 1 ( $P K D 1$ ) gene encodes a novel protein with multiple cell recognition domains. Nature Genet. 1995; 10:151-160. [PubMed: 7663510]

5. International Polycystic Kidney Disease Consortium. Polycystic kidney disease: the complete structure of the PKD1 gene and its protein. Cell. 1995; 81:289-298. [PubMed: 7736581]

6. Mochizuki T, Wu G, Hayashi T, et al. PKD2, a gene for polycystic kidney disease that encodes an integral membrane protein. Science. 1996; 272:1339-1342. [PubMed: 8650545]

7. Onuchic LF, Furu L, Nagasawa Y, et al. PKHD1, the polycystic kidney and hepatic disease 1 gene, encodes a novel large protein containing multiple immunoglobulin-like plexin- transcription-factor domains and parallel beta-helix 1 repeats. Am J Hum Genet. 2002; 70:1305-1317. [PubMed: 11898128]

8. Ward CJ, Hogan MC, Rossetti S, et al. The gene mutated in autosomal recessive polycystic kidney disease encodes a large, receptor-like protein. Nature Genet. 2002; 30:259-269. [PubMed: 11919560]

9. Xiong H, Chen Y, Yi Y, et al. A novel gene encoding a TIG multiple domain protein is a positional candidate for autosomal recessive polycystic kidney disease. Genomics. 2002; 80:96-104. [PubMed: 12079288]

10. Qian F, Germino FJ, Cai Y, et al. PKD1 interacts with PKD2 through a probable coiled-coil domain. Nature Genet. 1997; 16:179-183. [PubMed: 9171830]

11. Tsiokas L, Kim E, Arnould T, et al. Homo- and heterodimeric interactions between the gene products of PKD1 and PKD2. Proc Natl Acad Sci, USA. 1997; 94:6965-6970. [PubMed: 9192675]

12. Wang S, Zhang J, Nauli SM, et al. Fibrocystin/Polyductin, Found in the Same Protein Complex with Polycystin-2, Regulates Calcium Responses in Kidney Epithelia. Mol Cell Biol. 2007

13. Giamarchi A, Padilla F, Coste B, et al. The versatile nature of the calcium-permeable cation channel TRPP2. EMBO Rep. 2006; 7:787-793. [PubMed: 16880824]

14. Somlo, S.; Torres, VE.; Caplan, MJ. Autosomal Dominant Polycystic Kidney Disease and Inherited Cystic Disease. 4. Alpern, RJ.; Hebert, SC., editors. The Kidney; 2007. (in press)

15. Torres VE, Harris PC. Mechanisms of disease: autosomal dominant and recessive polycystic kidney diseases. Nature Clin Prac Nephro. 2006; 2:40-54.

16. Geng L, Burrow CR, Li HP, et al. Modification of the composition of polycystin-1 multiprotein complexes by calcium and tyrosine phosphorylation. Biochim Biophys Acta Mol Basis Dis. 1535; $1: 21-35$.

17. Huan Y, van Adelsberg J. Polycystin-1, the PKD1 gene product, is in a complex containing Ecadherin and the catenins. J Clin Invest. 1999; 104:1459-1468. [PubMed: 10562308]

18. Roitbak T, Ward CJ, Harris PC, et al. A polycystin-1 multiprotein complex is disrupted in polycystic kidney disease cells. Mol Biol Cell. 2004; 15:1334-1346. [PubMed: 14718571] 
19. Chauvet V, Tian X, Husson H, et al. Mechanical stimuli induce cleavage and nuclear translocation of the polycystin-1 C terminus. J Clin Invest. 2004; 114:1433-1443. [PubMed: 15545994]

20. Low SH, Vasanth S, Larson CH, et al. Polycystin-1, STAT6, and P100 function in a pathway that transduces ciliary mechanosensation and is activated in polycystic kidney disease. Dev Cell. 2006; 10:57-69. [PubMed: 16399078]

21. Hiesberger T, Gourley E, Erickson A, et al. Proteolytic cleavage and nuclear translocation of fibrocystin is regulated by intracellular $\mathrm{Ca} 2+$ and activation of protein kinase $\mathrm{C}$. J Biol Chem. 2006; 281:34357-34364. [PubMed: 16956880]

22. Kaimori JY, Nagasawa Y, Menezes LF, et al. Polyductin undergoes notch-like processing and regulated release from primary cilia. Hum Mol Genet. 2007; 16:942-956. [PubMed: 17470460]

23. Pazour GJ, San Agustin JT, Follit JA, et al. Polycystin-2 localizes to kidney cilia and the ciliary level is elevated in orpk mice with polycystic kidney disease. Curr Biol. 2002; 12:R378-380. [PubMed: 12062067]

24. Ward CJ, Yuan D, Masyuk TV, et al. Cellular and subcellular localization of the ARPKD protein; fibrocystin is expressed on primary cilia. Hum Mol Genet. 2003; 12:2703-2710. [PubMed: 12925574]

25. Yoder BK, Hou X, Guay-Woodford LM. The polycystic kidney disease proteins, polycystin-1, polycystin-2, polaris, and cystin, are co-localized in renal cilia. J Am Soc Nephrol. 2002; 13:25082516. [PubMed: 12239239]

26. McGrath J, Somlo S, Makova S, et al. Two populations of node monocilia initiate left-right asymmetry in the mouse. Cell. 2003; 114:61-73. [PubMed: 12859898]

27. Nauli SM, Alenghat FJ, Luo Y, et al. Polycystins 1 and 2 mediate mechanosensation in the primary cilium of kidney cells. Nat Genet. 2003; 33:129-137. [PubMed: 12514735]

28. Praetorius HA, Spring KR. Bending the MDCK cell primary cilium increases intracellular calcium. J Membr Biol. 2001; 184:71-79. [PubMed: 11687880]

29. Anyatonwu GI, Estrada M, Tian X, et al. Regulation of ryanodine receptor-dependent calcium signaling by polycystin-2. Proc Natl Acad Sci U S A. 2007; 104:6454-6459. [PubMed: 17404231]

30. Koulen P, Cai Y, Geng L, et al. Polycystin-2 is an intracellular calcium release channel. Nat Cell Biol. 2002; 4:191-197. [PubMed: 11854751]

31. Li Y, Wright JM, Qian F, et al. Polycystin 2 interacts with type I inositol 1,4,5-trisphosphate receptor to modulate intracellular Ca2+ signaling. J Biol Chem. 2005; 280:41298-41306. [PubMed: 16223735]

32. Tsiokas L, Arnould T, Shu C, et al. Specific association of the gene product of $\mathrm{PKD}_{2}$ with the TRPC1 channel. Proc Natl Acad Sci U S A. 1999; 96:3934-3939. [PubMed: 10097141]

33. Qian Q, Hunter LW, Li M, et al. Pkd2 haploinsufficiency alters intracellular calcium in vascular smooth muscle cells. Hum Mol Genet. 2003; 12:1875-1880. [PubMed: 12874107]

34. Yang J, Zhang S, Zhou Q, et al. PKHD1 gene silencing may cause cell abnormal proliferation through modulation of intracellular calcium in autosomal recessive polycystic kidney disease. J Biochem Mol Biol. 2007; 40:467-474. [PubMed: 17669261]

35. Chabardes D, Firsov D, Aarab L, et al. Localization of mRNAs encoding $\mathrm{Ca}^{2+}$-inhibitable adenylyl cyclases along the renal tubule. Functional consequences for regulation of the cAMP content. J Biol Chem. 1996; 271:19264-19271. [PubMed: 8702608]

36. Dousa TP. Cyclic- $3^{\prime}, 5^{\prime}$-nucleotide phosphodiesterase isozymes in cell biology and pathophysiology of the kidney. Kidney Int. 1999; 55:29-62. [PubMed: 9893113]

37. Houslay MD, Baillie GS. The role of ERK2 docking and phosphorylation of PDE4 cAMP phosphodiesterase isoforms in mediating cross-talk between the cAMP and ERK signalling pathways. Biochem Soc Trans. 2003; 31:1186-1190. [PubMed: 14641023]

38. Gattone VH, Wang X, Harris PC, et al. Inhibition of renal cystic disease development and progression by a vasopressin V2 receptor antagonist. Nature Med. 2003; 9:1323-1326. [PubMed: 14502283]

39. Torres VE, Wang X, Qian Q, et al. Effective treatment of an orthologous model of autosomal dominant polycystic kidney disease. Nature Med. 2004; 10:363-364. [PubMed: 14991049] 
40. Wang X, Gattone VH II, Harris PC, et al. Effectiveness of vasopressin V2 receptor antagonists OPC-31260 and OPC-41061 on polycystic kidney disease development in the PCK rat. J Am Soc Nephrol. 2005; 16:846-851. [PubMed: 15728778]

41. Yamaguchi T, Nagao S, Kasahara M, et al. Renal accumulation and excretion of cyclic adenosine monophosphate in a murine model of slowly progressive polycystic kidney disease. Am J Kidney Dis. 1997; 30:703-709. [PubMed: 9370187]

42. Grantham JJ. Lillian Jean Kaplan International Prize for advancement in the understanding of polycystic kidney disease. Understanding polycystic kidney disease: a systems biology approach. Kidney Int. 2003; 64:1157-1162. [PubMed: 12969132]

43. Hanaoka K, Guggino W. cAMP regulates cell proliferation and cyst formation in autosomal polycystic kidney disease cells. J Am Soc Nephrol. 2000; 11:1179-1187. [PubMed: 10864573]

44. Yamaguchi T, Wallace DP, Magenheimer BS, et al. Calcium restriction allows cAMP activation of the B-Raf/ERK pathway, switching cells to a cAMP-dependent growth-stimulated phenotype. J Biol Chem. 2004:40419-40430. [PubMed: 15263001]

45. Sweeney WE Jr, Chen Y, Nakanish K, et al. Treatment of polycystic kidney disease with a novel tyrosine kinase inhibitor. Kidney Int. 2000; 57:33-40. [PubMed: 10620185]

46. Shillingford JM, Murcia NS, Larson CH, et al. The mTOR pathway is regulated by polycystin-1, and its inhibition reverses renal cystogenesis in polycystic kidney disease. Proc Natl Acad Sci U S A. 2006; 103:5466-5471. [PubMed: 16567633]

47. Leuenroth SJ, Okuhara D, Shotwell JD, et al. Triptolide is a traditional Chinese medicine-derived inhibitor of polycystic kidney disease. Proc Natl Acad Sci U S A. 2007; 104:4389-4394. [PubMed: 17360534]

48. O'Sullivan D, Torres V, Gabow P, et al. Cystic fibrosis and the phenotypic expression of autosomal dominant polycystic kidney disease. Am J Kid Dis. 1998; 32:976-983. [PubMed: 9856513]

49. Xu N, Glockner JF, Rossetti S, et al. Autosomal dominant polycystic kidney disease coexisting with cystic fibrosis. J Nephrol. 2006; 19:529-534. [PubMed: 17048214]

50. Li H, Findlay IA, Sheppard DN. The relationship between cell proliferation, Cl- secretion, and renal cyst growth: a study using CFTR inhibitors. Kidney Int. 2004; 66:1926-1938. [PubMed: 15496164]

51. Magenheimer BS, St John PL, Isom KS, et al. Early embryonic renal tubules of wild-type and polycystic kidney disease kidneys respond to cAMP stimulation with cystic fibrosis transmembrane conductance regulator/ $\mathrm{Na}(+), \mathrm{K}(+), 2 \mathrm{Cl}(-)$ Co-transporter-dependent cystic dilation. J Am Soc Nephrol. 2006; 17:3424-3437. [PubMed: 17108316]

52. Torres VE, Sweeney WE Jr, Wang X, et al. EGF receptor tyrosine kinase inhibition attenuates the development of PKD in Han:SPRD rats. Kidney Int. 2003; 64:1573-1579. [PubMed: 14531789]

53. Sweeney E, Donohoe DL, Avner ED. Inhibition of ErbB2 Decreases c-SRC Activity and Ameliorates Renal and Biliary Cystic Abnormalities in the PCK Rat. JASN. 2005; 16:225A.

54. Sato Y, Harada K, Furubo S, et al. Inhibition of intrahepatic bile duct dilation of the polycystic kidney rat with a novel tyrosine kinase inhibitor gefitinib. Am J Pathol. 2006; 169:1238-1250. [PubMed: 17003482]

55. Torres VE, Sweeney WE Jr, Wang X, et al. Epidermal growth factor receptor tyrosine kinase inhibition is not protective in PCK rats. Kidney Int. 2004; 66:1766-1773. [PubMed: 15496147]

56. Bukanov N, Smith LA, Klinger K, et al. Long lasting arrest of murine polycystic kidney disease with CDK inhibitor R-Roscovitine. Nature. 2006 (In Press).

57. Omori S, Hida M, Fujita H, et al. Extracellular signal-regulated kinase inhibition slows disease progression in mice with polycystic kidney disease. J Am Soc Nephrol. 2006; 17:1604-1614. [PubMed: 16641154]

58. Sweeney WE, Avner ED. Inhibition in Autosomal Dominant Polycystic Kidney Disease (ADPKD). JASN. 2006; 17:778A.

59. Tao Y, Kim J, Schrier RW, et al. Rapamycin markedly slows disease progression in a rat model of polycystic kidney disease. J Am Soc Nephrol. 2005; 16:46-51. [PubMed: 15563559] 
60. Wahl PR, Serra AL, Le Hir M, et al. Inhibition of mTOR with sirolimus slows disease progression in Han:SPRD rats with autosomal dominant polycystic kidney disease (ADPKD). Nephrol Dial Transplant. 2006; 21:598-604. [PubMed: 16221708]

61. Torres VE. Vasopressin antagonists in polycystic kidney disease. Kidney Int. 2005; 68:2405-2418. [PubMed: 16221255]

62. Mutig K, Paliege A, Kahl T, et al. Vasopressin V2 receptor expression along rat, mouse, and human renal epithelia with focus on TAL. Am J Physiol Renal Physiol. 2007

63. Yasuda G, Jeffries WB. Regulation of cAMP production in initial and terminal inner medullary collecting ducts. Kidney Int. 1998; 54:80-86. [PubMed: 9648066]

64. Bankir L. Antidiuretic action of vasopressin: quantitative aspects and interaction between V1a and V2 receptor-mediated effects. Cardiovasc Res. 2001; 51:372-390. [PubMed: 11476728]

65. Liu L, Done SC, Khoshnoodi J, et al. Defective nephrin trafficking caused by missense mutations in the NPHS1 gene: insight into the mechanisms of congenital nephrotic syndrome. Hum Mol Genet. 2001; 10:2637-2644. [PubMed: 11726550]

66. Takei Y, Kawakoshi A, Tsukada T, et al. Contribution of comparative fish studies to general endocrinology: structure and function of some osmoregulatory hormones. J Exp Zoolog A Comp Exp Biol. 2006; 305:787-798.

67. Liu W, Morimoto T, Kondo Y, et al. “Avian-type” renal medullary tubule organization causes immaturity of urine-concentrating ability in neonates. Kidney Int. 2001; 60:680-693. [PubMed: 11473651]

68. Beyenbach KW. Kidneys sans glomeruli. Am J Physiol Renal Physiol. 2004; 286:F811-827. [PubMed: 15075177]

69. Danielsen H, Pedersen EB, Nielsen AH, et al. Expansion of extracellular volume in early polycystic kidney disease. Acta Med Scand. 1986; 219:399-405. [PubMed: 3716882]

70. Michalski A, Grzeszczak W. The effect of hypervolemia on electrolyte level and and level of volume regulating hormones in patients with autosomal dominant polycystic kidney disease. Pol Arch Med Wewn. 1996; 96:329-343. [PubMed: 9082344]

71. Seeman T, Dusek J, Vondrak K, et al. Renal concentrating capacity is linked to blood pressure in children with autosomal dominant polycystic kidney disease. Physiol Res. 2004; 53:629-634. [PubMed: 15588131]

72. Devuyst O, Burrow CR, Smith BL, et al. Expression of aquaporins-1 and -2 during nephrogenesis and in autosomal dominant polycystic kidney disease. Am J Physiol. 1996; 271:F169-183. [PubMed: 8760258]

73. Gattone VH, Maser RL, Tian C, et al. Developmental expression of urine concentration-associated genes and their altered expression in murine infantile-type polycystic kidney disease. Develop Gen. 1999; 24:309-318.

74. Yokoi H, Nagasaki H, Tachikawa K, et al. Adaptation to sustained high plasma vasopressin in water and electrolyte homeostasis in the rat transgenic for the metallothionein-vasopressin fusion gene. J Endocrinol. 2002; 173:23-33. [PubMed: 11927381]

75. Izumi Y, Nakayama Y, Mori T, et al. Downregulation of vasopressin V2 receptor promoter activity via V1a receptor pathway. Am J Physiol Renal Physiol. 2007; 292:F1418-1426. [PubMed: 17213462]

76. Bernat A, Hoffmann P, Dumas A, et al. V2 receptor antagonism of DDAVP-induced release of hemostasis factors in conscious dogs. J Pharmacol Exp Ther. 1997; 282:597-602. [PubMed: 9262320]

77. Ali F, Guglin M, Vaitkevicius P, et al. Therapeutic potential of vasopressin receptor antagonists. Drugs. 2007; 67:847-858. [PubMed: 17428103]

78. Greenberg A, Verbalis JG. Vasopressin receptor antagonists. Kidney Int. 2006; 69:2124-2130. [PubMed: 16672911]

79. Konstam MA, Gheorghiade M, Burnett JC Jr, et al. Effects of oral tolvaptan in patients hospitalized for worsening heart failure: the EVEREST Outcome Trial. JAMA. 2007; 297:13191331. [PubMed: 17384437] 
80. Gheorghiade M, Konstam MA, Burnett JC Jr, et al. Short-term clinical effects of tolvaptan, an oral vasopressin antagonist, in patients hospitalized for heart failure: the EVEREST Clinical Status Trials. JAMA. 2007; 297:1332-1343. [PubMed: 17384438]

81. Schrier RW, Gross P, Gheorghiade M, et al. Tolvaptan, a selective oral vasopressin V2-receptor antagonist, for hyponatremia. N Engl J Med. 2006; 355:2099-2112. [PubMed: 17105757]

82. Yamamura Y, Nakamura S, Itoh S, et al. OPC-41061, a highly potent human vasopressin $\mathrm{V}_{2^{-}}$ receptor antagonist: pharmacological profile and aquaretic effect by single and multiple oral dosing in rats. J Pharmacol Exp Ther. 1998; 287:860-867. [PubMed: 9864265]

83. Wang S, Gattone VH, Somlo S, et al. Effectiveness of OPC-41061 on polycystic kidney disease development in Pkd2WS25/-. J Am Soc Nephrol. 2005; 16:361A.

84. Gattone VH, Kinne Q, Torres VE. Efficacy of OPC-41061 in the treatment of murine nephronophthisis. J Am Soc Nephrol. 2005; 16:138A.

85. Wang X, Wu Y, Ward CJ, et al. Vasopressin directly regulates cyst growth in the PCK rat. J Am Soc Nephrol. 2007 (in press).

86. Bouby N, Bankir L, Trinh-Trang-Tan MM, et al. Selective ADH-induced hypertrophy of the medullary thick ascending limb in Brattleboro rats. Kidney Int. 1985; 28:456-466. [PubMed: 4068480]

87. Bankir L, Fischer C, Fischer S, et al. Adaptation of the rat kidney to altered water intake and urine concentration. Pflugers Arch. 1988; 412:42-53. [PubMed: 3174386]

88. Nagao S, kazuhiro N, Katsuyama M, et al. Increased water intake decreases progression of polycystic kidney disease in the PCK rat. J Am Soc Nephrol. 2006; 17:228-235.

89. Masyuk TV, Masyuk AI, Torres VE, et al. Octreotide inhibits hepatic cystogenesis in a rodent model of polycystic liver disease by reducing cholangiocyte adenosine $3^{\prime}, 5^{\prime}$-cyclic monophosphate. Gastroenterology. 2007; 132:1104-1116. [PubMed: 17383431]

90. Chang MY, Parker E, El Nahas M, et al. Endothelin B receptor blockade accelerates disease progression in a murine model of autosomal dominant polycystic kidney disease. J Am Soc Nephrol. 2007; 18:560-569. [PubMed: 17202412]

91. Balster DA, O’Dorisio MS, Summers MA, et al. Segmental expression of somatostatin receptor subtypes sst(1) and sst(2) in tubules and glomeruli of human kidney. Am J Physiol Renal Physiol. 2001; 280:F457-465. [PubMed: 11181407]

92. Ishikawa S, Saito T, Kuzuya T. Reversal of somatostatin inhibition of AVP-induced cAMP by pertussis toxin. Kidney Int. 1988; 33:536-542. [PubMed: 2896265]

93. Ray C, Carney S, Morgan T, et al. Somatostatin as a modulator of distal nephron water permeability. Clin Sci (Lond). 1993; 84:455-460. [PubMed: 8097684]

94. Oishi R, Nonoguchi H, Tomita K, et al. Endothelin-1 inhibits AVP-stimulated osmotic water permeability in rat inner medullary collecting duct. Am J Physiol. 1991; 261:F951-956. [PubMed: 1661085]

95. Hebert LA, Greene T, Levey A, et al. High urine volume and low urine osmolality are risk factors for faster progression of renal disease. Am J Kidney Dis. 2003; 41:962-971. [PubMed: 12722030]

96. Cowley AW Jr, Skelton MM, Kurth TM. Effects of long-term vasopressin receptor stimulation on medullary blood flow and arterial pressure. Am J Physiol. 1998; 275:R1420-1424. [PubMed: 9791056]

97. Fernandes S, Bruneval P, Hagege A, et al. Chronic V2 vasopressin receptor stimulation increases basal blood pressure and exacerbates deoxycorticosterone acetate-salt hypertension. Endocrinology. 2002; 143:2759-2766. [PubMed: 12072411]

98. Nicco C, Wittner M, DiStefano A, et al. Chronic exposure to vasopressin upregulates ENaC and sodium transport in the rat renal collecting duct and lung. Hypertension. 2001; 38:1143-1149. [PubMed: 11711512]

99. Sauter D, Fernandes S, Goncalves-Mendes N, et al. Long-term effects of vasopressin on the subcellular localization of ENaC in the renal collecting system. Kidney Int. 2006; 69:1024-1032. [PubMed: 16528252]

100. Szentivanyi M Jr, Park F, Maeda CY, et al. Nitric oxide in the renal medulla protects from vasopressin-induced hypertension. Hypertension. 2000; 35:740-745. [PubMed: 10720588] 
101. Kocaman O, Oflaz H, Yekeler E, et al. Endothelial dysfunction and increased carotid intimamedia thickness in patients with autosomal dominant polycystic kidney disease. Am J Kidney Dis. 2004; 43:854-860. [PubMed: 15112176]

102. Wang D, Iversen J, Wilcox CS, et al. Endothelial dysfunction and reduced nitric oxide in resistance arteries in autosomal-dominant polycystic kidney disease. Kidney Int. 2003; 64:13811388. [PubMed: 12969157]

103. Argent NB, Burrell LM, Goodship TH, et al. Osmoregulation of thirst and vasopressin release in severe chronic renal failure. Kidney Int. 1991; 39:295-300. [PubMed: 2002642]

104. Bankir L, Ahloulay M, Bouby N, et al. Is the process of urinary urea concentration responsible for a high glomerular filtration rate? J Am Soc Nephrol. 1993; 4:1091-1103. [PubMed: 8305636]

105. Bardoux P, Bichet DG, Martin H, et al. Vasopressin increases urinary albumin excretion in rats and humans: involvement of $\mathrm{V} 2$ receptors and the renin-angiotensin system. Nephrol Dial Transplant. 2003; 18:497-506. [PubMed: 12584270]

106. Bouby N, Bachmann S, Bichet D, et al. Effect of water intake on the progression of chronic renal failure in the 5/6 nephrectomized rat. Am J Physiol. 1990; 258:F973-979. [PubMed: 2184677]

107. Bouby N, Hassler C, Bankir L. Contribution of vasopressin to progression of chronic renal failure: study in Brattleboro rats. Life Sci. 1999; 65:991-1004. [PubMed: 10499867]

108. Sugiura T, Yamauchi A, Kitamura H, et al. High water intake ameliorates tubulointerstitial injury in rats with subtotal nephrectomy: possible role of TGF-b. Kidney Int. 1999; 55:1800-1810. [PubMed: 10231442]

109. Chapman AB, Torres VE, JGJ, et al. A phase IIB pilot study of the safety and efficacy of tolvaptan, a vasopressin V2 receptor antagonist (V2RA) in patents with ADPKD. J Am Soc Nephrol. 2005; 16:68A. [PubMed: 15537870]

110. Grantham JJ, Chapman AB, Torres VE, et al. Acute and chronic osmostasis after vassopressin V2 receptor inhibition with Tolvaptan in ADPKD. J Am Soc Nephrol. 2005; 16:361A.

111. Torres VE, Wang X, Ward CJ, et al. Urine aquaporin 2 and cyclic AMP responses to tolvaptan administration in autosomal dominant polycystic kidney disease. J Am Soc Nephrol. 2005; 16:361A.

112. Torres VE, Grantham JJ, Chapman AB, et al. Phase 2 open-label study to determine safety, tolerability and efficacy of split-dose Tolvaptan in ADPKD. J Am Soc Nephrol. 2007 (submitted to the ASN Meeting). 


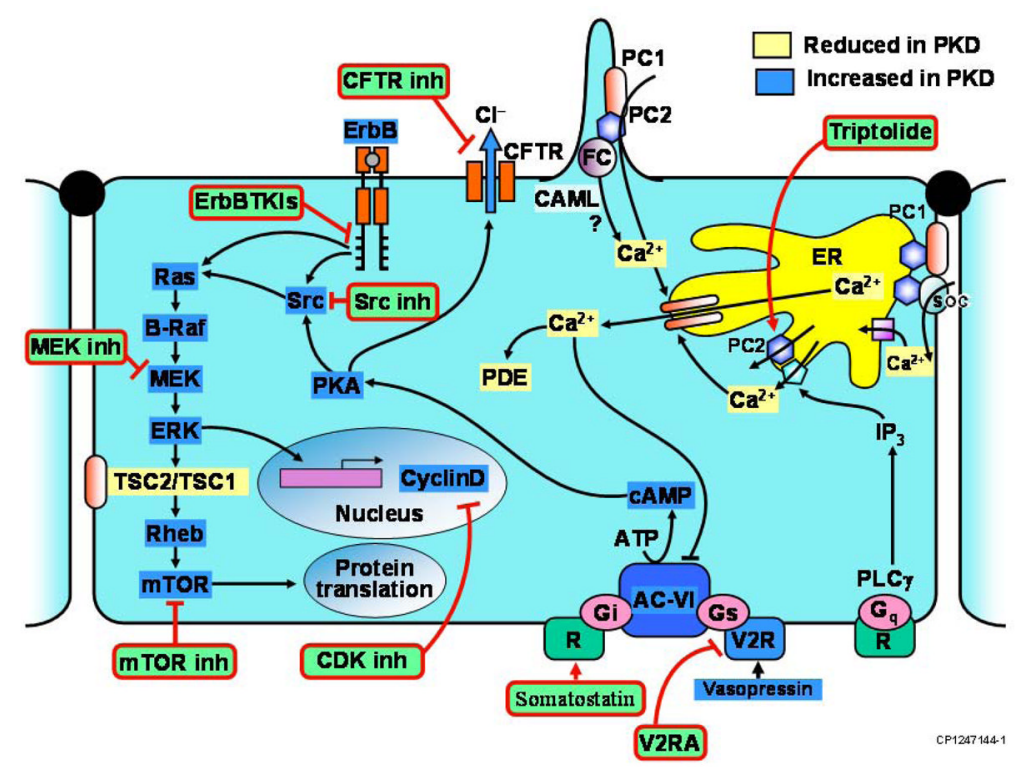

Figure 1.

Diagram depicting hypothetical pathways up- or down regulated in polycystic kidney disease and rationale for treatment with triptolide, CFTR inhibitors, ErbB tyrosine kinase, src, ERK or cyclin dependent kinase inhibitors, mTor inhibitors, somatostatin, and V2 receptor antagonists. Dysregulation of $\left[\mathrm{Ca}^{2+}\right]_{\mathrm{I}}$, increased concentrations of cAMP, and mislocalization of ErbB receptors occur in cells/kidneys bearing PKD mutations. Increased accumulation of cAMP in polycystic kidneys may result from: (i) disruption of the polycystin complex, since PC1 may act as a Gi protein-coupled receptor; (ii) stimulation of $\mathrm{Ca}^{2+}$ inhibitable AC6 and/or inhibition of $\mathrm{Ca}^{2+}$-dependent PDE1 by a reduction in $\left[\mathrm{Ca}^{2+}\right]_{\mathrm{I}}$; (iii) increased levels of circulating vasopressin due to an intrinsic concentrating defect; (iv) upregulation of vasopressin V2 receptors. Increased cAMP levels contribute to cystogenesis by stimulating chloride and fluid secretion. In addition, stimulates mitogen-activated protein kinase/extracellularly regulated kinase (MAPK/ERK) signaling and cell proliferation in a Src and Ras dependent manner in cyst derived cells or in wild type tubular epithelial cells treated with $\mathrm{Ca}^{2+}$ channel blockers or in a low $\mathrm{Ca}^{2+}$ medium. Activation of mislocalized ErbB receptors by ligands present in cystic fluid also contributes to the stimulation of MAPK/ERK signaling and cell proliferation. Phosphorylation of tuberin by ERK and Akt (or inadequate targeting to the plasma membrane due to defective interaction with polycystin 1) may lead to the dissociation of tuberin and hamartin and lead to the activation of Rheb and mTOR. AC-VI, adenylate cyclase 6; CFTR, cystic fibrosis transmembrane conductance regulator; ER, endoplasmic reticulum; MAPK, mitogen-activated protein kinase; mTOR, mammalian target of rapamycin; PC1, polycystin-1; PC2, polycystin-2; PDE, phosphodiesterase; PKA, protein kinase A; R, somatostatin sst2 receptor; TSC, tuberous sclerosis proteins tuberin (TSC2) and hamartin (TSC1); V2R, vasopressin V2 receptor; V2RA, vasopressin V2 receptor antagonists. Modified from Torres et al. Lancet 369, 1287-1301 (2007) 